\title{
Fedj el-Koucha
}

(voir B98, Bouïa, E.B. X, p. 1589-1592 et D81, Djorf Torba, E.B. XVI, p. 2477-2488)

\section{G. Camps}

\section{OpenEdition}

\section{Journals}

\section{Édition électronique}

URL : http://journals.openedition.org/encyclopedieberbere/2027

DOI : 10.4000/encyclopedieberbere.2027

ISSN : 2262-7197

Éditeur

Peeters Publishers

\section{Édition imprimée}

Date de publication : 1 août 1997

Pagination : 2749-2752

ISBN : 2-85744-948-8

ISSN : 1015-7344

Référence électronique

G. Camps, «Fedj el-Koucha », Encyclopédie berbère [En ligne], 18| 1997, document F13, mis en ligne le

01 juin 2011, consulté le 10 décembre 2020. URL : http://journals.openedition.org/

encyclopedieberbere/2027 ; DOI : https://doi.org/10.4000/encyclopedieberbere.2027

Ce document a été généré automatiquement le 10 décembre 2020.

(c) Tous droits réservés 


\section{Fedj el-Koucha}

(voir B98, Bouïa, E.B. X, p. 1589-1592 et D81, Djorf Torba, E.B. XVI, p. 2477-2488)

\section{G. Camps}

1 L'un des deux grands tumulus à chapelle fouillés par E Battestini, en 1936, dans la région de Négrine (Némencha, Algérie) et qui servit de prototype aux monuments à chapelle puisqu'il fut le premier, avec celui de Besseriani, dans lequel fut reconnue la présence d'une "chapelle". Depuis, d'autres monuments à chapelle ont été reconnus et fouillés en Mauritanie, au Tafilalet (Bouïa*, Taouz*), dans la Hamada du Guir (Djorf Torba*) et dans l'Atlas saharien. Dans la même région de Négrine, près de Ferkane, un troisième tumulus du même type fut découvert et fouillé dans l'oued Djerch par D. Grébénart en 1960.

2 Au Fedj el-Koucha, le tumulus circulaire a un diamètre de $28 \mathrm{~m}$, c'est le plus grand des monuments de la région; ceux de Besseriani et de l'oued Djerch ont respectivement 18 et $22 \mathrm{~m}$ de diamètre. Le monument de Fedj el-Koucha doit son nom à la présence, dans la partie est du tumulus, d'une chapelle en cul de four. C'est la plus complexe des trois connues dans la région. Celle du tumulus de l'oued Djerch n'est qu'un trapèze allongé dont le fond est occupé par une niche voûtée de plein cintre ; à Besseriani, la chapelle plus complexe a un plan tréflé. Celle de Fedj el-Koucha avait un plus grand développement : la même chapelle tréflée $(2,05 \mathrm{~m}$ x 2,90 m) est précédée d'une vaste salle elliptique dont le grand axe dépasse $9 \mathrm{~m}$ et le petit $4 \mathrm{~m}$. Cette salle possédait quatre colonnes qui supportaient la couverture vraisemblablement en bois, révélée par la présence d'une importante couche de cendres et de charbons de bois sur le sol. Avant son éboulement, cette couverture était à une hauteur de deux mètres. Comme à Besseriani, un enduit fait de plâtre et de sable, recouvre les parois constituées, comme la masse du tumulus, de moellons de grès. Dans les deux chapelles un barbouillage d'ocre rouge recouvrait cet enduit dans sa totalité : on a pu le reconnaître aussi sur le sol autour des colonnes.

3 La construction des chapelles est peu soignée, les lobes du trèfle sont inégaux, les arêtes et toutes les courbes sont hésitantes. Dans l'axe de la chapelle, approximativement au centre du tumulus fut creusée la fosse funéraire. Cet 
emplacement est identique dans les trois tumulus à chapelle connus dans le sud des Nemencha. Au Fedj el-Koucha cette fosse présente un décrochement qui retient quelques grosses pierres servant de fermeture. Cet ouverture est particulièrement étroite, sa largeur ne dépasse pas $26 \mathrm{~cm}$; comme le dit E. Battestini, l'inhumation dut être difficile, cependant le squelette est bien conservé. L'inhumation a été faite en décubitus latéral légèrement fléchi et le corps avait été revêtu d'une pièce d'étoffe fine, en laine a-t-il semblé au fouilleur ; elle recouvrait aussi le visage. L'envers de ce suaire portait un enduit brun qui ne semble pas avoir été analysé.

Comme à Besseriani et à l'oued Djerch, aucun mobilier n'accompagnait l'inhumation. Il est donc difficile de fixer la chronologie de ces tumulus à chapelle du sud des Némencha. Cependant le monument de Fedj el-Koucha présente un grand nombre de graffiti qui peuvent contribuer à sa datation. Ces graffiti sont tracés à la pointe fine sur l'enduit ocré qui revêt les parois de la chapelle. E. Battestini a pris soin d'en relever une vingtaine. Ils sont tous d'un schématisme extrême; on peut reconnaître, suivant leur fréquence, des personnages filiformes à cheval, ou à pied se battant à l'épée, des motifs végétaux et géométriques. Une inscription libyque a été relevée par le fouilleur, elle compte sept (peut-être huit) caractères de lecture incertaine : D.T.M.S.R.T.N. selon E. Battestini, G.T. ?S ?M.T. selon G. Camps. On ne sait pas quand l'alphabet libyque fut abandonné par les Berbères de la région, mais, fort loin vers l'ouest, les recherches de L. Leschi au Centenarium d'Aqua Viva près de M'Doukal (Barika) ont livré, dans un cimetière renfermant des lampes à canal du $v^{e}$ siècle, un plat sur le fond duquel avait été gravé un shamesh (S) libyque et un autre portant un motif identique à l'aleph néopunique. Ainsi, dans le sud de la Numidie, dans une zone plus romanisée que celle de Négrine, l'usage des alphabets libyque et néo-punique s'était maintenu jusqu'au v $v^{\mathrm{e}}$ siècle de notre ère. 
Tumulus à chapelle de Besseriani et de Fedj el-Koucha.

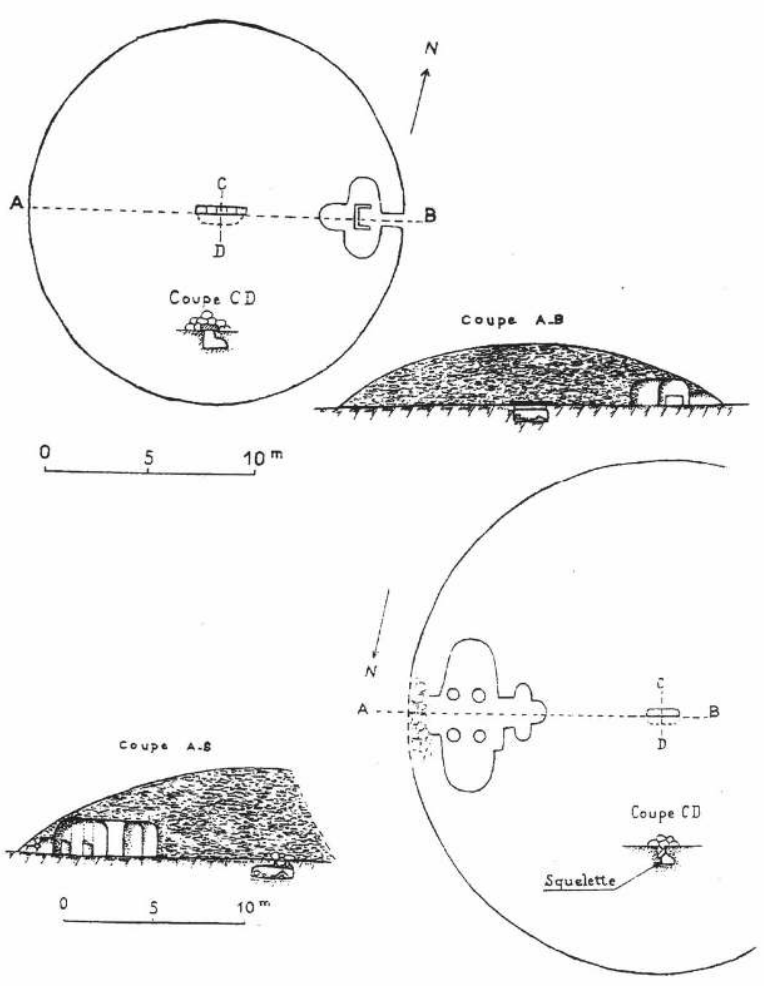

Dessin Battistini.

5 Il est remarquable que le tumulus de l'oued Djerch ait été de même illustré par des graffiti d'un style identique à ceux de Fedj el-Koucha et représentant les mêmes motifs. Dans les relevés de D. Grébénart on retrouve la même prédominance de chevaux montés ou libres, de personnages à pied, d'éléments végétaux et de figures géométriques. Comme à Fedj el-Koucha une inscription libyque mutilée, comprenant les trois lettres I M R. accompagne ces graffiti. Un texte de cinq lignes très peu lisible comprend des caractères d'aspect néopunique.

6 Très loin à l'ouest, dans les confins algéro-marocains, à Djorf Torba*, nous retrouvons dans les chapelles de certains tumulus des dalles gravées ou peintes qui, elles aussi, accordent une place de prédilection au cheval (ici admirablement traité dans un style naturaliste) et aux personnages dont les vêtements sont figurés avec minutie ; comme dans les tumulus de la région de Négrine, ces scènes sont accompagnées d'inscriptions libyques. L'une d'elles représente d'une famille dont deux personnages semblent bien brandir des croix processionnelles. Si notre interprétation est exacte, il faut croire que certains constructeurs de tumulus à chapelle de Djorf Torba étaient gagnés au christianisme. Le plan tréflé des chapelles des monuments de la région de Négrine est une forme totalement inconnue dans l'architecture berbère protohistorique, on peut se poser la question de ses origines et y voir peut-être une influence chrétienne de l'époque byzantine. E. Battestini avait déjà noté que la construction du monument de Besseriani était postérieure à la destruction de la ville romaine de Majores. 
Inscription libyque et graffiti sur les parois de la chapelle de Fedj el-Koucha.

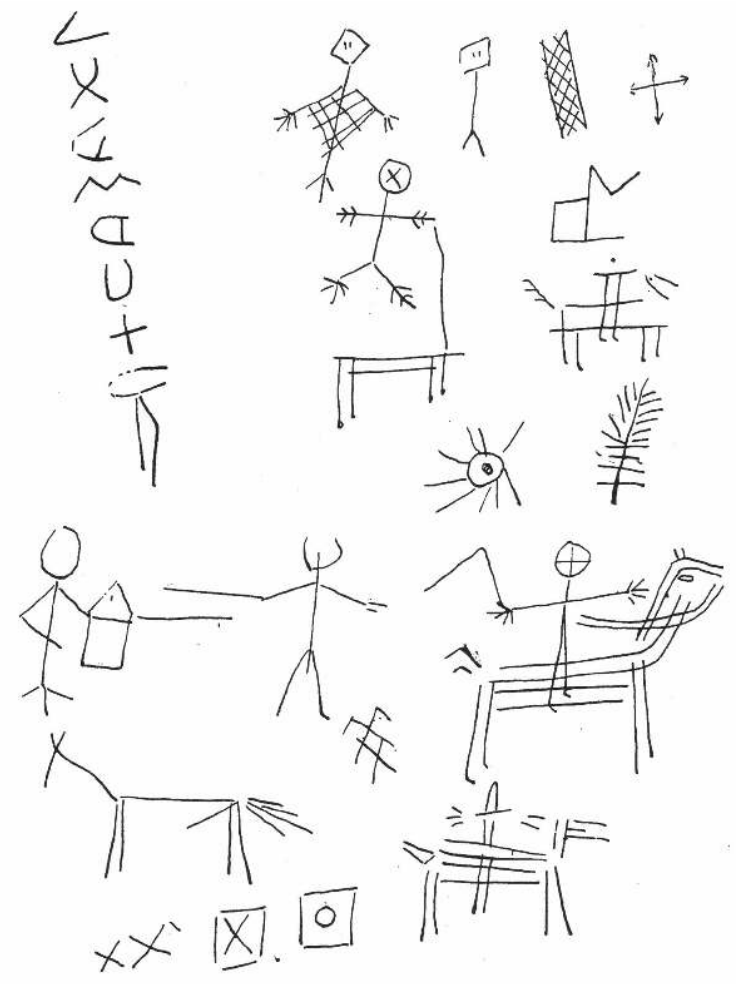

Relevé Battestini.

\section{BIBLIOGRAPHIE}

BATTESTINI E., "Note sur deux tumuli de la région de Négrine”, Rec. de la Soc. de Prétest. et d'Archéol. de Tébessa, 1936-1937, p. 183-195.

GREBENART D., "Sépultures protohistoriques de la région de Ferkane”, Libyca, t. IX-X, 1961-1962, p. $171-184$.

CAMPS G, Monuments et rites funéraires protohistoriques, Paris, A.M.G., 1961, p. 182-184.

CAMPS G, "Les tumulus à chapelle du Sahara protohistorique. Tombes sanctuaires des Gétules". Hommages à Jacques Millotte, Besançon, Les Belles Lettres, 1984, p. 561-572.

INDEX

Mots-clés : Protohistoire, Algérie 